\title{
Emerging treatment options for the treatment of neuroblastoma: potential role of perifosine
}

This article was published in the following Dove Press journal:

OncoTargets and Therapy

I March 2012

Number of times this article has been viewed

\author{
Weili Sun' \\ Shakeel Modak ${ }^{2}$ \\ 'Department of Pediatrics, Keck \\ School of Medicine, University of \\ Southern California, Children's \\ Hospital of Los Angeles, Los Angeles, \\ CA, USA; ${ }^{2}$ Department of Pediatrics, \\ Memorial Sloan-Kettering Cancer \\ Center, New York, NY, USA
}

Correspondence: Shakeel Modak Department of Pediatrics, Memorial Sloan-Kettering Cancer Center, I 275 York Avenue, New York, NY 10065, USA

$\mathrm{Tel}+\mathrm{I} 2126397623$

$\mathrm{Fax}+\mathrm{I} 2127173239$

Email modaks@mskcc.org

\begin{abstract}
Achieving a cure for high-risk neuroblastoma, the most common extracranial solid tumor in children, remains a formidable task despite the recent addition of antibody-mediated anti-GD2 immunotherapy to established multimodality therapy. The PI3K/Akt pathway is a pivotal signaling pathway utilized by a plethora of receptor tyrosine kinases that contribute to the aggressive phenotype of high-risk neuroblastoma. Akt is aberrantly activated in high-risk neuroblastoma and is therefore an attractive therapeutic target. Perifosine is the best-characterized Akt inhibitor in preclinical studies and in clinical trials in adults, although safety in children is not yet confirmed. It is a synthetic third-generation alkylphospholipid with good oral bioavailability and modest side effects. Perifosine targets the lipid-binding PH domain of Akt and inhibits the translocation of Akt to the cell membrane, an essential step for Akt activation. It decreases Akt phosphorylation and increases caspase-dependent apoptosis in neuroblastoma cell lines, inhibits growth of neuroblastoma xenografts, and overcomes RTK/ligand-mediated chemoresistance. It is currently being studied in two Phase I clinical trials in children with recurrent or refractory solid tumors including neuroblastoma. In the single agent trial (ClinicalTrials.gov identifier NCT00776867), maximum tolerated dose has not yet been reached and pharmacokinetic data has been accrued. In the second study (ClinicalTrials.gov identifier NCT01049841), patients are treated with a combination of perifosine and the mTOR-inhibitor temsirolimus based on preclinical data showing synergy of the two agents, and the premise that direct Akt inhibition may overcome Akt activation secondary to mTOR inhibition. Based on results from adult trials, it is unlikely that perifosine alone will produce dramatic therapeutic effects against high-risk neuroblastoma. However, given the recent encouraging early-phase combination therapy results in adults with multiple myeloma and colorectal carcinoma, rational perifosine-containing combination regimens hold promise for neuroblastoma therapy. These will be explored after safety in children is established in Phase I studies.
\end{abstract}

Keywords: neuroblastoma, Akt pathway, perifosine

\section{Introduction}

Curing neuroblastoma, the most frequent pediatric solid tumor outside the central nervous system, remains a challenge. Although it accounts for approximately $7 \%$ of malignancies in patients younger than 15 years, neuroblastoma accounts for $15 \%$ of all pediatric oncology deaths. ${ }^{1}$ Neuroblastoma arises from the neural crest cells of the sympathetic nervous system, and exhibits a diverse clinical picture. Infants may experience complete regression of the disease without any therapy; and cytotoxic therapy can be withheld for most patients with locoregional disease. However, most patients have metastatic disease at diagnosis, and the prognosis for those diagnosed $>18$ months of age or those with $M Y C N$-amplified disease is poor despite aggressive multimodality therapy. 
Tumors initially respond to intensive chemotherapy, surgery, and radiotherapy; however most patients relapse and become resistant to chemotherapy. ${ }^{2}$ Disialoganglioside (GD2) has thus far been the most-frequently targeted tumor antigen on neuroblastoma. ${ }^{3}$ Antibody-based anti-GD2 immunotherapy with or without myeloablative therapy and autologous stem cell transplant has shown encouraging results with significantly improved short-term survival. ${ }^{4,5}$ However, currently, long-term event-free survival for patients diagnosed with high-risk disease (which constitute the majority of neuroblastoma cases) as reported in multi-center studies is $<40 \%$. $^{6-9}$ Patients with recurrent neuroblastoma have a far worse outcome. ${ }^{10}$ Early tumor detection by screening did not reduce tumor-related mortality. ${ }^{11,12}$ Therefore, new therapeutic strategies are needed to improve the outcome.

Advances in our understanding of the biology of neuroblastoma have given us insights in identifying neuroblastoma-specific molecular targets for novel therapy. Certain genetic alterations are associated with more aggressive phenotype and high-risk disease. These include MYCN-amplification, 1p deletion, loss of heterozygosity at chromosome $11 \mathrm{q}$, and $17 \mathrm{q}$ gain. ${ }^{13}$ However, corresponding viable targetable molecules for therapy have not been identified. Recently, mutations and amplifications of anaplastic lymphoma kinase (ALK) have been described in small subsets of patients of neuroblastoma. ${ }^{14-16}$ This has led to the hope that ALK inhibitors may provide effective therapeutic options for patients with neuroblastoma, and early phase studies are underway. In addition, high-risk neuroblastoma is associated with elevated expression of the neurotrophinreceptor tropomyosin receptor kinase TrkB which is considered to act as an oncogenic kinase in a subset of patients. ${ }^{17} \mathrm{~A}$ safe and biologically effective dose of the multikinase inhibitor lestaurtinib which has anti-TrkB activity has recently been established, though single agent activity against neuroblastoma is modest. ${ }^{18,19}$ TrkB activates the downstream phosphatidylinositol 3'-kinase (PI3K)/Akt pathway as do a plethora of other receptor tyrosine kinases (RTKs) implicated in neuroblastoma pathogenesis and behavior. ${ }^{20,21}$ Therefore Akt inhibition may be therapeutically effective for high-risk neuroblastoma. In this review, we focus on the role of the Akt pathway in neuroblastoma and specifically, a possible therapeutic role for the Akt inhibitor perifosine.

\section{PI3K/Akt signaling pathway}

The PI3K/Akt pathway is a key signaling pathway that contributes to cell growth, proliferation, survival, angiogenesis, and glucose metabolism. ${ }^{22-24}$ Upon growth factor binding, transmembrane RTKs are activated by phosphorylation that in turn activates PI3K. ${ }^{25}$ Activation of PI3K generates phosphatidylinositol-3,4,5-trisphosphate (PIP3) which then anchors the serine/threonine kinase Akt to the plasma membrane via the binding of PIP3 to the pleckstrin homology $(\mathrm{PH})$ domain of Akt. ${ }^{26}$ The binding triggers a conformational change of Akt and releases the autoinhibition function of the $\mathrm{PH}$ domain. This results in the exposure of the two crucial amino acid sites: threonine 308 (Thr308) in the activation loop of the kinase; and serine 473 (Ser473) at the C-terminus for phosphorylation. Activation of Akt requires both translocation to the plasma membrane and phosphorylation of the two key residues by phosphoinositide-dependent kinase (PDK)-1 and PDK-2. ${ }^{27}$ Once activated, Akt dissociates from the plasma membrane and moves to various cellular compartments and targets downstream substrates including mammalian target of rapamycin (mTOR) pathway. ${ }^{22,28}$ A key negative regulator of Akt signaling is the tumor suppressor gene phosphatase and tensin homolog (PTEN). PTEN can dephosphorylate PIP3 and thereby inhibit PI3K/Akt signaling. ${ }^{28}$ This pathway is also negatively regulated by protein serine/threonine phosphatase which specifically dephosphorylates Ser473. ${ }^{22,29,30}$ (Figure 1).

\section{PI3K/Akt pathway and neuroblastoma}

Aberrant activation of the Akt pathway has been widely implicated in many cancers. ${ }^{31}$ It is one of the most frequently involved pathways in sporadic human tumors, with estimates suggesting that mutation in one or another PI3K/ Akt pathway component accounts for up to $30 \%$ of all human cancers. ${ }^{23,32}$ Conversely PTEN is considered to be a major tumor suppressor. ${ }^{33}$ In one study, tissue microarray analysis revealed phosphorylation of Akt at Ser473 and Thr308 in $57 \%$ of primary neuroblastoma samples tested. Activation was highly correlated with the phosphorylation of S6 ribosomal protein, a downstream target of mTOR pathway. Activation of the Akt pathway correlated with several parameters of aggressive disease, including MYCN amplification, chromosome $1 \mathrm{p}$ aberrations, advanced disease stage, older age at diagnosis, and unfavorable histology. ${ }^{34}$ Phosphorylation of Akt correlated with decreased event-free or overall survival of neuroblastoma patients, but S6 or extracellular signalregulated kinase (ERK) phosphorylation did not. ${ }^{34}$ Another group studied 39 high-risk neuroblastoma samples using phospho-antibodies specifically for the phosphorylated proteins in $\mathrm{PI} 3 \mathrm{~K} / \mathrm{AKT}$ pathways. It was found that most of 


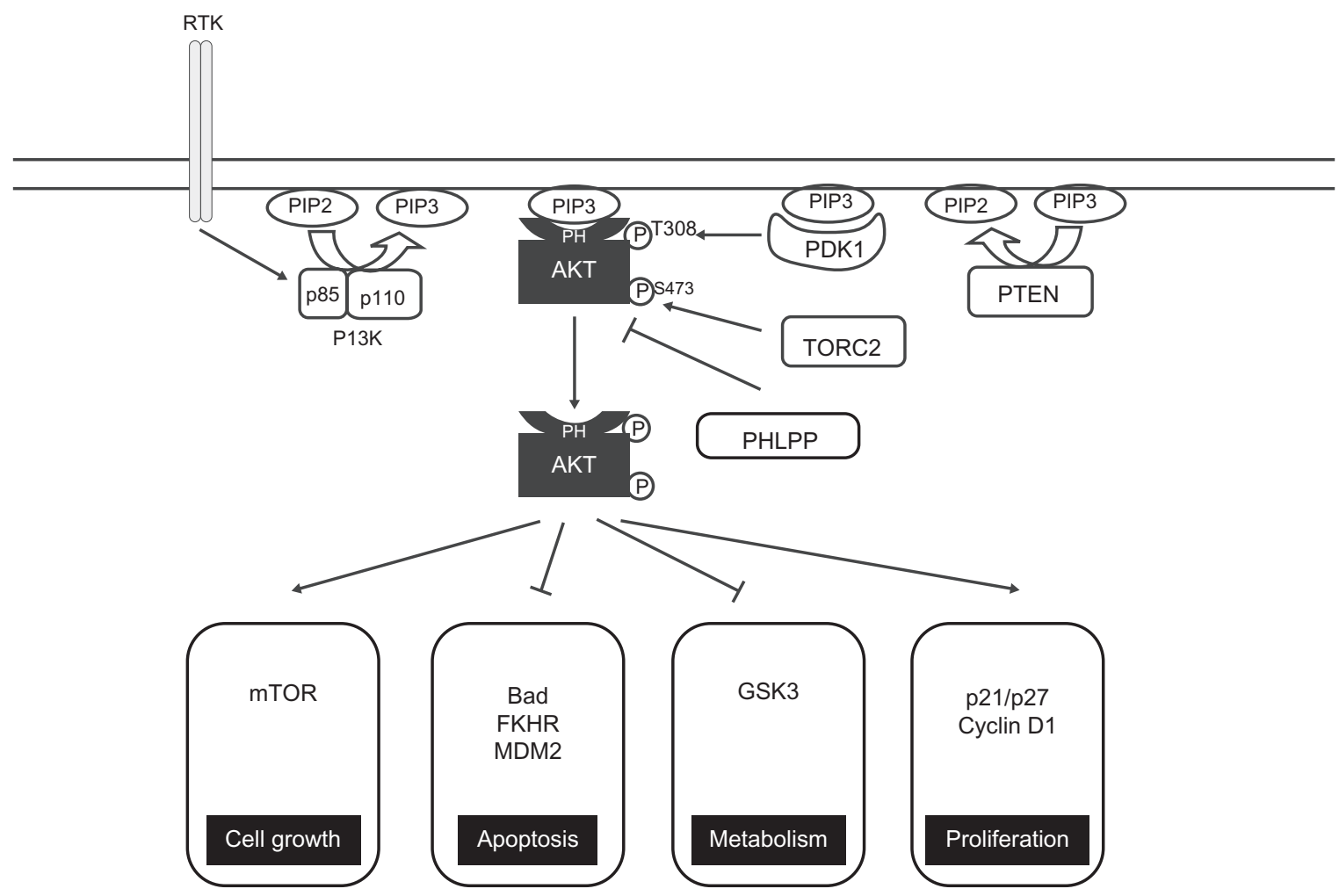

Figure I Diagrammatic representation of the Akt signaling pathway.

Notes: Activation of receptor tyrosine kinase (RTK) by growth factor binding activates PIK3. Activated PI3K phosphorylates PIP2 and generates PIP3, a reaction that can be reversed by PTEN. The PH domain of Akt binds to PIP3, which then triggers a conformational change of Akt that results in the phosphorylation of two critical amino acids, Thr308 and Ser473 by PDK-I and TORC2 respectively. The phosphorylated Akt then dissociates from the plasma membrane and targets downstream pathways including cell growth, survival, proliferation, and metabolism. Besides PTEN, this pathway is also negatively regulated by PHLPP, a protein serine/threonine phosphatase that can dephosphorylate Ser473 of Akt.

Abbreviations: PIP2, Phosphatidylinositol (4,5)-bisphosphate; PIP3, Phosphatidylinositol (3,4,5)-trisphosphate; PDKI, 3-Phosphoinositide-dependent protein kinase I; TORC2, mammalian target of rapamycin complex 2; PTEN, Phosphatase and tensin homolog; PHLPP, PH domain and Leucine rich repeat protein phosphatases; mTOR, mammalian target of rapamycin Bad, Bcl-xL/Bcl-2-associated death promoter; FKHR, Forkhead transcription factors; MDM2, mouse double minute 2; GSK3, glycogen synthase kinase 3.

the tumors were positive for PI3Kp85 and PI3Kp110, as well as for phosphorylated Akt, mTOR, and S6. ${ }^{35}$ In another study, expression of activated Akt and mTOR was detected in all 34 primary neuroblastoma tissue samples tested, but not in non-malignant adrenal medullas. ${ }^{36}$ Lower levels of Akt activation were detected in low-risk neuroblastoma (tumors expected to mature or regress spontaneously) detected by mass screening when compared to classical neuroblastoma. ${ }^{37}$ In vitro studies suggest that the PI3K/Akt plays a key role in neuroblastoma cell survival mediated by RTK ligands/RTKs including TrkB/brain-derived neurotrophic factor (BDNF), ${ }^{38}$ insulin-like growth factor (IGF)/IGF-receptor, ${ }^{39,40}$ epidermal growth factor (EGF)/EGF-receptor, ${ }^{41,42}$ platelet-derived growth factor (PDGF)/PDGF-receptor, ${ }^{43}$ and vascular endothelial growth factor (VEGF)/VEGF-receptor. ${ }^{4-46}$ Several studies also indicate that Akt is involved in controlling apoptosis in neuroblastoma cells through caspasedependent and caspase-independent mechanisms, ${ }^{47,48}$ in protein synthesis and cell growth via downstream mTOR signaling, ${ }^{49}$ and in cell cycle control via interaction with glycogen synthase kinase-3 $\beta$ (GSK3). ${ }^{50,51}$ Recently, Akt regulation in neuroblastoma cells has been linked to the micro RNAs miR-14952 and miR-184. ${ }^{53}$ Activation of the Akt pathway in neuroblastoma can be caused by mutation or overexpression of RTKs and/or their ligands. Besides the above growth factors/receptors, activating ALK mutations have been shown to enhance Akt activity. ${ }^{16,54,55}$ The Akt pathway can also be aberrantly activated by inactivation of tumor suppressor PTEN by homozygous deletion or promoter hypermethylation. ${ }^{56,57}$ In addition, several other proteins can influence Akt activation or inhibition in neuroblastoma. These include TNF-related apoptosis inducing ligand (TRAIL), ${ }^{58} \mathrm{PKC}$ family proteins,${ }^{59}$ and FOXO3a. ${ }^{60}$ In summary, based on current studies, Akt is aberrantly activated in a majority of high-risk neuroblastic tumors, and appears to be an important mediator of the cancer phenotype in neuroblastoma. However, unlike in some adult cancers, Akt/ PI3 K mutations have not been detected in neuroblastoma including in a high-throughput sequenom-based analysis of a large number of primary tumors. ${ }^{61}$ 


\section{Targeting the Akt pathway}

Recent attention has been focused on the concept of "oncogene addiction," which hypothesizes that cancer cells are dependent on, or "addicted" to, one or a few genes for both maintenance and survival of the malignant cells. ${ }^{62}$ Therefore, inhibiting only one or a few of these abnormalities may inhibit cancer cell growth and translate to improved outcome. Because Akt is at the pivotal nodal point in the signaling pathway of a majority of RTKs, and the activation of the Akt pathway has been frequently found in cancers, it is an attractive target for novel anticancer drugs. If Akt is inhibited, the survival signaling of most RTKs will be blocked, obviating the need to identify tumor-specific "drug-able" genetic/epigenetic changes or patient tumor-specific RTKs. Substrates downstream of Akt critical for cell survival can be cell type specific, and inhibition of individual substrates may miss key targets that are responsible for cell survival and proliferation. Directly targeting Akt can circumvent feedback activation of Akt that has been observed with mTOR inhibition. ${ }^{22,69}$ Therefore, direct targeting of Akt, especially in tumors with an activated Akt pathway such as neuroblastoma, has the potential to be therapeutically effective. Various strategies have been used to develop Akt inhibitors, including screening small molecules that target the ATP-binding domain or the PH domain of Akt, and designing peptides that model the interaction of Akt with inhibitory binding proteins. ${ }^{63,68,69}$ Several Akt inhibitors are in early phase clinical trials for a variety of cancers ${ }^{64}$ Perifosine is the most well characterized and clinically evaluated Akt inhibitor thus far.

\section{Perifosine: an anticancer Akt inhibitor}

Perifosine is a synthetic oral alkylphospholipid with a piperidine head group. It is a third generation anti-tumor alkylphospholipid analog related to miltefosine and edelfosine, but with better oral availability and fewer gastrointestinal side effects. ${ }^{65}$ The synthetic alkylphospholipids are membrane-permeable ether lipids that are easily inserted into the outer leaflet of the plasma membrane and subsequently induce profound biological changes and ultimately lead to cell death. ${ }^{63,66,68,69}$ Perifosine targets the lipid-binding PH domain of Akt and inhibits the translocation of Akt to the cell membrane, an essential step for the activation of Akt. ${ }^{67-70}$ Perifosine has also been shown to inhibit MAPK ${ }^{71}$ and $\mathrm{JNK}^{72}$ pathways. In vitro, perifosine inhibits Akt at low micromolar concentrations and causes apoptosis in many human cancers including multiple myeloma, T-acute lymphoblastic leukemia, acute myeloid leukemia, non-small cell lung carcinoma, prostate carcinoma, hepatocellular carcinoma, ovarian carcinoma, and medulloblastoma. ${ }^{72-80}$ In vivo, Akt inhibition by perifosine has been documented in xenograft mouse models of multiple myeloma, ${ }^{81-83}$ glioma, ${ }^{84}$ Waldenstrom's macroglobulinemia, ${ }^{85}$ breast, ovarian, and prostate cancer. ${ }^{86}$ Cell lines with activating Akt pathways are more sensitive to perifosine in vitro than those without, and the ability of perifosine to inhibit tumor in vivo is correlated with the decreases in phosphorylation of Akt and other components of the pathway in the tumor. ${ }^{86}$ In pediatric tumors other than neuroblastoma, perifosine-induced Akt inhibition has been demonstrated in a brainstem glioma mouse model, ${ }^{87}$ and it was shown to act as a radiation-sensitizer in murine medulloblastoma. ${ }^{88}$

Perifosine has been tested in several clinical trials in adults with various tumor types. In Phase I studies, the maximumtolerated dose was determined to be $150 \mathrm{mg}$ orally for each of the four loading doses on day 1 followed by $100 \mathrm{mg}$ orally once daily as maintenance. ${ }^{89}$ The maximum tolerated maintenance daily dose of perifosine was $200 \mathrm{mg} / \mathrm{day},{ }^{90}$ and the half-life was estimated to be about 4 days. ${ }^{91}$ Perifosine was well tolerated in general, with common toxicities being gastrointestinal symptoms and fatigue. Toxicities were less than grade 3 in the majority of patients. Bone marrow suppression was minor. ${ }^{89,90}$ Multiple adult Phase II trials using perifosine in various solid tumor and sarcomas have been completed. Single agent anti-tumor activity was modest and was noted against sarcoma, ${ }^{92}$ Waldenstrom's macroglobulinemia, ${ }^{93}$ renal cell carcinoma, and non-small cell lung cancer. ${ }^{64}$ A randomized placebo-controlled Phase II study comparing perifosine plus capecitabine to capecitabine alone as second or third-line therapy in patients with metastatic colorectal carcinoma showed significantly better time to progression and overall survival for patients treated with the combination. ${ }^{94}$ Similarly, the combination of perifosine plus bortezomib and dexamethasone demonstrated encouraging activity in pretreated bortezomib-exposed patients with resistant multiple myeloma. ${ }^{95}$ Phase III studies have now been initiated for both colorectal cancer and for multiple myeloma.

\section{Perifosine: preclinical studies in neuroblastoma}

Constitutively activated Akt has been detected in neuroblastoma cell lines and increases cell survival; ${ }^{38}$ in primary tumors. It is associated with high-risk disease. ${ }^{34}$

Activation of neuroblastoma RTKs can increase Akt activation and mediate chemoresistance, warranting consideration of Akt as a tumor target for therapy. 
Perifosine in $\mu \mathrm{M}$ concentrations decreased Akt phosphorylation and increased caspase-dependent apoptosis in four different neuroblastoma cell lines bearing different genetic and biological characteristics resembling a spectrum of high-risk neuroblastoma. ${ }^{96}$ In xenograft models, perifosine inhibited the growth of neuroblastoma tumors with an improved survival of perifosine-treated mice with minimal toxicity. Xenografts in perifosine-treated mice showed inhibition of Akt activation and induction of caspase-dependent apoptosis. ${ }^{96}$ Interestingly, neuroblastoma cell lines with both wild-type and mutant ALK were sensitive to perifosine. The role of perifosine in overcoming chemoresistance was tested in a TrkB-expressing neuroblastoma cell line TB3 which demonstrates BDNF-induced Akt activation. Pre-treatment with perifosine blocked brain-derived neurotrophic factor (BDNF)/TrkB-induced TrkB phosphorylation and attenuated BDNF-mediated etoposide chemoresistance in vitro. In mice bearing TB3 xenografts, the combination of perifosine and etoposide reduced tumor growth significantly when compared to treatment with either drug alone, suggesting a role for perifosine in overcoming chemoresistance mediated by Akt-activation. ${ }^{97}$

\section{Rationale for combination strategies with perifosine}

The results of Phase II trials using perifosine as a single agent are modest. ${ }^{64}$ However, data from perifosine-including combination therapies for multiple myeloma and colorectal cancer are encouraging. ${ }^{94,95}$ It is likely that cancers depend on more than one pathway for their proliferation and survival and inhibitors of a single deregulated pathway may be insufficient to induce cell death. Indeed in vitro, perifosine has been shown to have a synergistic antitumor effect when combined with various biological agents including UCN- $01,{ }^{98}$ histone deacetylase inhibitors, ${ }^{99}$ TRAIL, ${ }^{73,100}$ erlotinib,${ }^{75}$ cetuximab, ${ }^{71}$ and 17-DMAG. ${ }^{101}$ In particular, simultaneous targeting of the Akt pathway by perifosine and mTOR inhibition induced cell death and decreased proliferation in murine glioblastoma studies. ${ }^{102}$ In addition, perifosine synergizes with conventional chemotherapy agents against multiple myeloma, ${ }^{82}$ endometrial cancer, ${ }^{103}$ and acute myeloid leukemia. ${ }^{104}$ In murine medulloblastoma and brain stem glioma model, perifosine has been shown to sensitize tumor cells to radiation therapy ${ }^{88,105}$ Taken together, these preclinical data suggest that combination therapy can increase the cytotoxic effect of perifosine, and Akt inhibition can sensitize the responsiveness of tumor cells to chemotherapy and radiation therapy. In preclinical studies of TrkB-expressing neuroblastoma xenografts, both perifosine and lestaurtinib ${ }^{106}$ synergize with chemotherapy, suggesting that TrkB-mediated chemoresistance can be overcome by inhibition of RTK-driven survival pathways. Since perifosine has little bone marrow toxicity, combination conventional chemotherapy with perifosine could lead to being more effective in tumor killing without major myelosuppression.

\section{Perifosine: clinical studies in neuroblastoma}

Perifosine is currently being tested in two ongoing pediatric Phase I studies, both being conducted at Memorial Sloan-Kettering Cancer Center. The first is a Phase I dose escalation study of perifosine as a single agent for recurrent pediatric solid tumors including neuroblastoma (ClinicalTrials.gov identifier number NCT00776867). This has a standard Phase I design to determine the maximal tolerated dose (MTD) of perifosine in children. Given the restrictions of perifosine oral formulation (only available in $50 \mathrm{mg}$ tablets), the drug is not dosed per surface area, but in five groups where grouping is based on body surface area. All patients receive an oral load on day 1 (50-300 mg) followed by maintenance doses $(50-200 \mathrm{mg}$ ) ranging from once every 4 days to once daily. This corresponds to an initial dose level of approximately $25 \mathrm{mg} / \mathrm{m}^{2} /$ day with increments of $25 \mathrm{mg} / \mathrm{m}^{2} /$ day per dose level. Perifosine is a potential substrate for the cytochrome P450 system which is induced by enzyme inducing anti-epileptic drugs; hence, patients are not allowed to receive the latter concurrently with perifosine. Dose-limiting toxicities monitored for include any non-hematological toxicity $\geq$ grade 3 and severe myelosuppression. Secondary objectives include assessment of perifosine pharmacokinetics and correlation of molecular features of tumors with response, if any. Preliminary data were reported on nine patients (including two patients with neuroblastoma) treated at the first three dose levels. No dose-limiting toxicities were reported and MTD has not yet been reached. Grade 2 toxicities possibly related to perifosine included asthenia (22\%), asymptomatic hepatic transaminase elevation $(22 \%)$, neutropenia $(33 \%)$, leukopenia (11\%), hyperglycemia (22\%), hypomagnesemia (22\%), hypophosphatemia (11\%), and colitis which resolved despite drug continuation (11\%). Preliminary pharmacokinetic data resulted in the following steady state serum levels: $14.1 \pm 4 \mu \mathrm{M}$ for dose level 1, 32.8 $\pm 8.1 \mu \mathrm{M}$ for dose level 2, and $31.6 \pm 7.8 \mu \mathrm{M}$ for dose level 3. ${ }^{107}$ Both patients did not show disease progression at $9+$ months on therapy. ${ }^{108}$ Given the excellent safety profile observed at the third dose level, additional patients with neuroblastoma have been treated 
at dose level 3 for a preliminary evaluation of efficacy of perifosine monotherapy against neuroblastoma. To date, an additional twelve patients with neuroblastoma have been treated on the protocol.

The second study investigates the combination of perifosine and temsirolimus in a Phase I clinical trial for patients with recurrent pediatric solid tumors (ClinicalTrials. gov identifier number NCT01049841). It seeks to build on the hypothesis that Akt inhibition by perifosine, in conjunction with disruption of the downstream mTOR pathway by the rapamycin analog temsirolimus, can have a synergistic anti-tumor effect. Akt targeting with perifosine can potentially circumvent the activation of Akt observed with mTOR inhibition. ${ }^{109}$ Furthermore, with the exception of gastrointestinal side effects, the two drugs have non-overlapping toxicities, possibly allowing therapeutic use in combination without major toxicity. The MTD of temsirolimus as a single agent in children was determined to be $150 \mathrm{mg} / \mathrm{m}^{2} /$ dose weekly intravenously ${ }^{110}$ but a dose of $75 \mathrm{mg} / \mathrm{m}^{2} /$ day has been adopted for Phase II pediatric studies. ${ }^{111}$ The primary objective is to determine the maximum tolerated doses of perifosine and temsirolimus when used in combination. A dosing strategy similar to that used for the single agent perifosine study is used for daily oral perifosine dosing. Temsirolimus is first escalated from 25 to $75 \mathrm{mg} / \mathrm{m}^{2} \mathrm{IV}$ every 4 weeks with perifosine escalation in three cohorts after the final dose of temsirolimus is reached. Secondary objectives include measurement of perifosine and temsirolimus pharmacokinetics and acquiring preliminary data regarding efficacy of the combination. The design of further clinical trials using perifosine in pediatrics will likely be predicated on the establishment of perifosine MTD in the above two studies.

\section{Conclusion}

Clinical and laboratory research over the last several decades has made considerable progress in understanding the biology and improving the therapy of neuroblastoma. However, the long-term survival rate for the high-risk patients remains $<40 \%$. Therapy aimed at newer therapeutic targets should therefore be explored. Akt has a potentially pivotal role in mediating RTK signaling in neuroblastoma. The Akt pathway is activated in the majority of neuroblastoma and is associated with a poor prognosis. Preclinical data suggests that perifosine, an Akt inhibitor, is an effective therapeutic agent with tolerable toxicity. Ongoing Phase I pediatric studies will establish the safety profile for this agent in children, but lessons learned from perifosine trials in adults suggest that the single agent perifosine is unlikely to yield impressive therapeutic results. Based on an understanding of its underlying mechanism of action, recent preclinical data from neuroblastoma cell lines and xenograft studies, and encouraging clinical data from early phase studies in adult cancers, perifosine in combination with other novel agents or established chemotherapy has the potential to add to the increasing armamentarium of therapies being developed for the treatment of high-risk neuroblastoma.

\section{Disclosure}

The authors report no conflicts of interest in this work.

\section{References}

1 Maris JM. Recent advances in neuroblastoma. $N$ Engl J Med. 2010; 362(23):2202-2211.

2. Modak S, Cheung NK. Neuroblastoma: Therapeutic strategies for a clinical enigma. Cancer Treat Rev. 2010;36(4):307-317.

3. Modak S, Cheung NK. Disialoganglioside directed immunotherapy of neuroblastoma. Cancer Invest. 2007;25(1):67-77.

4. Yu AL, Gilman AL, Ozkaynak MF, et al. Anti-GD2 antibody with GMCSF, interleukin-2, and isotretinoin for neuroblastoma. $N$ Engl J Med. 2010;363(14):1324-1334.

5. Cheung NK, Sowers R, Vickers AJ, Cheung IY, Kushner BH, Gorlick R. FCGR2A polymorphism is correlated with clinical outcome after immunotherapy of neuroblastoma with anti-GD2 antibody and granulocyte macrophage colony-stimulating factor. J Clin Oncol. 2006;24(18):2885-2890.

6. Moroz V, Machin D, Faldum A, et al. Changes over three decades in outcome and the prognostic influence of age-at-diagnosis in young patients with neuroblastoma: a report from the International Neuroblastoma Risk Group Project. Eur J Cancer. 2011;47(4):561-571.

7. Canete A, Gerrard M, Rubie H, et al. Poor survival for infants with MYCN-amplified metastatic neuroblastoma despite intensified treatment: the International Society of Paediatric Oncology European Neuroblastoma Experience. J Clin Oncol. 2009;27(7):1014-1019.

8. De Bernardi B, Nicolas B, Boni L, et al. Disseminated neuroblastoma in children older than one year at diagnosis: comparable results with three consecutive high-dose protocols adopted by the Italian Co-Operative Group for Neuroblastoma. J Clin Oncol. 2003;21(8):1592-1601.

9. Matthay KK, Villablanca JG, Seeger RC, et al. Treatment of high-risk neuroblastoma with intensive chemotherapy, radiotherapy, autologous bone marrow transplantation, and 13-cis-retinoic acid. Children's Cancer Group. N Engl J Med. 1999;341(16):1165-1173.

10. London WB, Castel V, Monclair T, et al. Clinical and biologic features predictive of survival after relapse of neuroblastoma: a report from the International Neuroblastoma Risk Group project. J Clin Oncol. 2011;29(24):3286-3292.

11. Schilling FH, Spix C, Berthold F, et al. Neuroblastoma screening at one year of age. $N$ Engl J Med. 2002;346(14):1047-1053.

12. Woods WG, Gao RN, Shuster JJ, et al. Screening of infants and mortality due to neuroblastoma. N Engl J Med. 2002;346(14):1041-1046.

13. Maris JM, Hogarty MD, Bagatell R, Cohn SL. Neuroblastoma. Lancet. 2007;369(9579):2106-2120.

14. Caren H, Abel F, Kogner P, Martinsson T. High incidence of DNA mutations and gene amplifications of the ALK gene in advanced sporadic neuroblastoma tumours. Biochem J. 2008;416(2):153-159.

15. George RE, Sanda T, Hanna M, et al. Activating mutations in ALK provide a therapeutic target in neuroblastoma. Nature. 2008; 455(7215):975-978. 
16. Mosse YP, Laudenslager M, Longo L, et al. Identification of ALK as a major familial neuroblastoma predisposition gene. Nature. 2008;455(7215):930-935.

17. Nakagawara A, Azar CG, Scavarda NJ, Brodeur GM. Expression and function of TRK-B and BDNF in human neuroblastomas. Mol Cell Biol. 1994;14(1):759-767.

18. Norris RE, Minturn JE, Brodeur GM, Maris JM, Adamson PC. Preclinical evaluation of lestaurtinib (CEP-701) in combination with retinoids for neuroblastoma. Cancer Chemother Pharmacol. 2011;68(6):1469-1475.

19. Minturn JE, Evans AE, Villablanca JG, et al. Phase I trial of lestaurtinib for children with refractory neuroblastoma: a new approaches to neuroblastoma therapy consortium study. Cancer Chemother Pharmacol. 2011;68(4):1057-1065.

20. Li Z, Thiele CJ. Targeting Akt to increase the sensitivity of neuroblastoma to chemotherapy: lessons learned from the brain-derived neurotrophic factor/TrkB signal transduction pathway. Expert Opin Ther Targets. 2007;11(12):1611-1621.

21. Sartelet H, Oligny LL, Vassal G. AKT pathway in neuroblastoma and its therapeutic implication. Expert Rev Anticancer Ther. 2008;8(5): 757-769.

22. Manning BD, Cantley LC. AKT/PKB signaling: navigating downstream. Cell. 2007;129(7):1261-1274.

23. Shaw RJ, Cantley LC. Ras, PI(3)K and mTOR signalling controls tumour cell growth. Nature. 2006;441(7092):424-430.

24. Brazil DP, Park J, Hemmings BA. PKB binding proteins. Getting in on the Akt. Cell. 2002;111(3):293-303.

25. Blume-Jensen P, Hunter T. Oncogenic kinase signalling. Nature. 2001;411(6835):355-365.

26. Franke TF, Yang SI, Chan TO, et al. The protein kinase encoded by the Akt proto-oncogene is a target of the PDGF-activated phosphatidylinositol 3-kinase. Cell. 1995;81(5):727-736.

27. Vivanco I, Sawyers CL. The phosphatidylinositol 3-Kinase AKT pathway in human cancer. Nat Rev Cancer. 2002;2(7):489-501.

28. Cully M, You H, Levine AJ, Mak TW. Beyond PTEN mutations: the PI3K pathway as an integrator of multiple inputs during tumorigenesis. Nat Rev Cancer. 2006;6(3):184-192.

29. Bellacosa A, Kumar CC, Di Cristofano A, Testa JR. Activation of AKT kinases in cancer: implications for therapeutic targeting. Adv Cancer Res. 2005;94:29-86.

30. Engelman JA, Luo J, Cantley LC. The evolution of phosphatidylinositol 3-kinases as regulators of growth and metabolism. Nat Rev Genet. 2006;7(8):606-619.

31. Hennessy BT, Smith DL, Ram PT, Lu Y, Mills GB. Exploiting the PI3K/AKT pathway for cancer drug discovery. Nat Rev Drug Discov. 2005;4(12):988-1004.

32. Luo J, Manning BD, Cantley LC. Targeting the PI3K-Akt pathway in human cancer: rationale and promise. Cancer Cell. 2003;4(4): 257-262.

33. Cantley LC, Neel BG. New insights into tumor suppression: PTEN suppresses tumor formation by restraining the phosphoinositide 3-kinase/ AKT pathway. Proc Natl Acad Sci US A. 1999;96(8):4240-4245.

34. Opel D, Poremba C, Simon T, Debatin KM, Fulda S. Activation of Akt predicts poor outcome in neuroblastoma. Cancer Res. 2007;67(2): 735-745.

35. Izycka-Swieszewska E, Drozynska E, Rzepko R, et al. Analysis of PI3K/ AKT/mTOR signalling pathway in high risk neuroblastic tumours. Pol J Pathol. 2010;61(4):192-198.

36. Johnsen JI, Segerstrom L, Orrego A, et al. Inhibitors of mammalian target of rapamycin downregulate $\mathrm{MYCN}$ protein expression and inhibit neuroblastoma growth in vitro and in vivo. Oncogene. 2008;27(20): 2910-2922.

37. Sartelet H, Ohta S, Barrette S, et al. High level of apoptosis and low AKT activation in mass screening as opposed to standard neuroblastoma. Histopathology. 2010;56(5):607-616.

38. Li Z, Jaboin J, Dennis PA, Thiele CJ. Genetic and pharmacologic identification of Akt as a mediator of brain-derived neurotrophic factor/ TrkB rescue of neuroblastoma cells from chemotherapy-induced cell death. Cancer Res. 2005;65(6):2070-2075.
39. Kim B, van Golen CM, Feldman EL. Insulin-like growth factor-I signaling in human neuroblastoma cells. Oncogene. 2004;23(1):130-141.

40. Coulter DW, Blatt J, D'Ercole AJ, Moats-Staats BM. IGF-I receptor inhibition combined with rapamycin or temsirolimus inhibits neuroblastoma cell growth. Anticancer Res. 2008;28(3A):1509-1516.

41. Evangelopoulos ME, Weis J, Kruttgen A. Signalling pathways leading to neuroblastoma differentiation after serum withdrawal: HDL blocks neuroblastoma differentiation by inhibition of EGFR. Oncogene. 2005;24(20):3309-3318.

42. Chiu B, Mirkin B, Madonna MB. Mitogenic and apoptotic actions of epidermal growth factor on neuroblastoma cells are concentration-dependent. J Surg Res. 2006;135(2):209-212.

43. Servidei T, Riccardi A, Sanguinetti M, Dominici C, Riccardi R. Increased sensitivity to the platelet-derived growth factor (PDGF) receptor inhibitor STI571 in chemoresistant glioma cells is associated with enhanced PDGF-BB-mediated signaling and STI571-induced Akt inactivation. J Cell Physiol. 2006;208(1):220-228.

44. Beierle EA, Nagaram A, Dai W, Iyengar M, Chen MK. VEGF-mediated survivin expression in neuroblastoma cells. J Surg Res. 2005;127(1): 21-28.

45. Ngan ES, Sit FY, Lee K, et al. Implications of endocrine gland-derived vascular endothelial growth factor/prokineticin-1 signaling in human neuroblastoma progression. Clin Cancer Res. 2007;13(3):868-875.

46. Beppu K, Nakamura K, Linehan WM, Rapisarda A, Thiele CJ. Topotecan blocks hypoxia-inducible factor-1 alpha and vascular endothelial growth factor expression induced by insulin-like growth factor-I in neuroblastoma cells. Cancer Res. 2005;65(11):4775-4781.

47. Mookherjee P, Quintanilla R, Roh MS, Zmijewska AA, Jope RS, Johnson GV. Mitochondrial-targeted active Akt protects SH-SY5Y neuroblastoma cells from staurosporine-induced apoptotic cell death. J Cell Biochem. 2007;102(1):196-210.

48. Francois F, Grimes ML. Phosphorylation-dependent Akt cleavage in neural cell in vitro reconstitution of apoptosis. $J$ Neurochem. 1999;73(4):1773-1776.

49. Datta SR, Brunet A, Greenberg ME. Cellular survival: a play in three Akts. Genes Dev. 1999;13(22):2905-2927.

50. Dozza B, Smith MA, Perry G, Tabaton M, Strocchi P. Regulation of glycogen synthase kinase-3beta by products of lipid peroxidation in human neuroblastoma cells. J Neurochem. 2004;89(5):1224-1232.

51. Zhou XW, Winblad B, Guan Z, Pei JJ. Interactions between glycogen synthase kinase 3 beta, protein kinase $\mathrm{B}$, and protein phosphatase $2 \mathrm{~A}$ in tau phosphorylation in mouse N2a neuroblastoma cells. J Alzheimers Dis. 2009;17(4):929-937.

52. Lin RJ, Lin YC, Chen J, et al. microRNA signature and expression of Dicer and Drosha can predict prognosis and delineate risk groups in neuroblastoma. Cancer Res. 2010;70(20):7841-7850.

53. Foley NH, Bray IM, Tivnan A, et al. MicroRNA-184 inhibits neuroblastoma cell survival through targeting the serine/threonine kinase AKT2. Mol Cancer. 2010;9:83.

54. Chen Y, Takita J, Choi YL, et al. Oncogenic mutations of ALK kinase in neuroblastoma. Nature. 2008;455(7215):971-974.

55. Janoueix-Lerosey I, Lequin D, Brugieres L, et al. Somatic and germline activating mutations of the ALK kinase receptor in neuroblastoma. Nature. 2008;455(7215):967-970.

56. Hoebeeck J, Michels E, Pattyn F, et al. Aberrant methylation of candidate tumor suppressor genes in neuroblastoma. Cancer Lett. 2009;273(2):336-346

57. Munoz J, Lazcoz P, Inda MM, et al. Homozygous deletion and expression of PTEN and DMBT1 in human primary neuroblastoma and cell lines. Int J Cancer. 2004;109(5):673-679.

58. Kim S, Kang J, Qiao J, Thomas RP, Evers BM, Chung DH. Phosphatidylinositol 3-kinase inhibition down-regulates survivin and facilitates TRAIL-mediated apoptosis in neuroblastomas. J Pediatr Surg. 2004;39(4):516-521.

59. Bronisz A, Gajkowska B, Domanska-Janik K. PKC and Raf-1 inhibition-related apoptotic signalling in N2a cells. J Neurochem. 2002;81(6):1176-1184. 
60. Zhu W, Bijur GN, Styles NA, Li X. Regulation of FOXO3a by brain-derived neurotrophic factor in differentiated human SH-SY5Y neuroblastoma cells. Brain Res Mol Brain Res. 2004;126(1):45-56.

61. Shukla NN, Ameur N, Yilmaz I, et al. Oncogene Mutation Profiling of Pediatric Solid Tumors Reveals Significant Subsets of Embryonal Rhabdomyosarcoma and Neuroblastoma with Mutated Genes in Growth Signaling Pathways. Clin Cancer Res. 2011. [Epub ahead of print.]

62. Weinstein IB, Joe AK. Mechanisms of disease: Oncogene addictiona rationale for molecular targeting in cancer therapy. Nat Clin Pract Oncol 2006;3(8):448-457.

63. Barnett SF, Bilodeau MT, Lindsley CW. The Akt/PKB family of protein kinases: a review of small molecule inhibitors and progress towards target validation. Curr Top Med Chem. 2005;5(2):109-125.

64. Pal SK, Reckamp K, Yu H, Figlin RA. Akt inhibitors in clinical development for the treatment of cancer. Expert Opin Investig Drugs. 2010;19(11):1355-1366.

65. Hilgard P, Klenner T, Stekar J, Nossner G, Kutscher B, Engel J. D-21266, a new heterocyclic alkylphospholipid with antitumour activity. Eur $J$ Cancer. 1997;33(3):442-446.

66. Vink SR, van Blitterswijk WJ, Schellens JH, Verheij M. Rationale and clinical application of alkylphospholipid analogues in combination with radiotherapy. Cancer Treat Rev. 2007;33(2):191-202.

67. Kondapaka SB, Singh SS, Dasmahapatra GP, Sausville EA, Roy KK. Perifosine, a novel alkylphospholipid, inhibits protein kinase B activation. Mol Cancer Ther. 2003;2(11):1093-1103.

68. Gills JJ, Dennis PA. Perifosine: update on a novel Akt inhibitor. Curr Oncol Rep. 2009;11(2):102-110.

69. LoPiccolo J, Granville CA, Gills JJ, Dennis PA. Targeting Akt in cancer therapy. Anticancer Drugs. 2007;18(8):861-874.

70. Ruiter GA, Zerp SF, Bartelink H, van Blitterswijk WJ, Verheij M. Anti-cancer alkyl-lysophospholipids inhibit the phosphatidylinositol 3-kinase-Akt/PKB survival pathway. Anticancer Drugs. 2003;14(2): 167-173.

71. Li X, Luwor R, LuY, Liang K, Fan Z. Enhancement of antitumor activity of the anti-EGF receptor monoclonal antibody cetuximab/C225 by perifosine in PTEN-deficient cancer cells. Oncogene. 2006;25(4):525-535.

72. Chiarini F, Del Sole M, Mongiorgi S, et al. The novel Akt inhibitor, perifosine, induces caspase-dependent apoptosis and downregulates P-glycoprotein expression in multidrug-resistant human T-acute leukemia cells by a JNK-dependent mechanism. Leukemia. 2008;22(6):1106-1116.

73. Elrod HA, Lin YD, Yue P, et al. The alkylphospholipid perifosine induces apoptosis of human lung cancer cells requiring inhibition of Akt and activation of the extrinsic apoptotic pathway. Mol Cancer Ther. 2007;6(7):2029-2038

74. Tazzari PL, Tabellini G, Ricci F, et al. Synergistic proapoptotic activity of recombinant TRAIL plus the Akt inhibitor Perifosine in acute myelogenous leukemia cells. Cancer Res. 2008;68(22):9394-9403.

75. Festuccia C, Gravina GL, Muzi P, et al. Akt down-modulation induces apoptosis of human prostate cancer cells and synergizes with EGFR tyrosine kinase inhibitors. Prostate. 2008;68(9):965-974.

76. Floryk D, Thompson TC. Perifosine induces differentiation and cell death in prostate cancer cells. Cancer Lett. 2008;266(2):216-226.

77. Nyakern M, Cappellini A, Mantovani I, Martelli AM. Synergistic induction of apoptosis in human leukemia $\mathrm{T}$ cells by the Akt inhibitor perifosine and etoposide through activation of intrinsic and Fas-mediated extrinsic cell death pathways. Mol Cancer Ther. 2006;5(6): 1559-1570.

78. Fei HR, Chen G, Wang JM, Wang FZ. Perifosine induces cell cycle arrest and apoptosis in human hepatocellular carcinoma cell lines by blockade of Akt phosphorylation. Cytotechnology. 2010;62(5):449-460.

79. Engel JB, Schonhals T, Hausler S, et al. Induction of programmed cell death by inhibition of AKT with the alkylphosphocholine perifosine in in vitro models of platinum sensitive and resistant ovarian cancers. Arch Gynecol Obstet. 2011;283(3):603-610.

80. Kumar A, Fillmore HL, Kadian R, Broaddus WC, Tye GW, Van Meter TE. The alkylphospholipid perifosine induces apoptosis and p21-mediated cell cycle arrest in medulloblastoma. Mol Cancer Res. 2009; 7(11):1813-1821.
81. Catley L, Hideshima T, Chauhan D, et al. Alkyl phospholipid perifosine induces myeloid hyperplasia in a murine myeloma model. Exp Hematol. 2007;35(7):1038-1046.

82. Hideshima T, Catley L, Yasui H, et al. Perifosine, an oral bioactive novel alkylphospholipid, inhibits Akt and induces in vitro and in vivo cytotoxicity in human multiple myeloma cells. Blood. 2006;107(10):4053-4062.

83. Hideshima T, Catley L, Raje N, et al. Inhibition of Akt induces significant downregulation of survivin and cytotoxicity in human multiple myeloma cells. Br J Haematol. 2007;138(6):783-791.

84. Momota H, Nerio E, Holland EC. Perifosine inhibits multiple signaling pathways in glial progenitors and cooperates with temozolomide to arrest cell proliferation in gliomas in vivo. Cancer Res. 2005;65(16):7429-7435.

85. Leleu X, Jia X, Runnels J, et al. The Akt pathway regulates survival and homing in Waldenstrom macroglobulinemia. Blood. 2007;110(13):4417-4426

86. Hennessy BT, Lu Y, Poradosu E, et al. Pharmacodynamic markers of perifosine efficacy. Clin Cancer Res. 2007;13(24):7421-7431.

87. Becher OJ, Hambardzumyan D, Walker TR, et al. Preclinical evaluation of radiation and perifosine in a genetically and histologically accurate model of brainstem glioma. Cancer Res. 2010;70(6):2548-2557.

88. Hambardzumyan D, Becher OJ, Rosenblum MK, Pandolfi PP, ManovaTodorova K, Holland EC. PI3K pathway regulates survival of cancer stem cells residing in the perivascular niche following radiation in medulloblastoma in vivo. Genes Dev. 2008;22(4):436-448.

89. Van Ummersen L, Binger K, Volkman J, et al. A phase I trial of perifosine (NSC 639966) on a loading dose/maintenance dose schedule in patients with advanced cancer. Clin Cancer Res. 2004; 10(22):7450-7456.

90. Crul M, Rosing H, de Klerk GJ, et al. Phase I and pharmacological study of daily oral administration of perifosine (D-21266) in patients with advanced solid tumours. Eur J Cancer. 2002;38(12):1615-1621.

91. Unger C, Berdel W, Hanauske AR, Sindermann H, Engel J, Mross K. First-time-in-man and pharmacokinetic study of weekly oral perifosine in patients with solid tumours. Eur J Cancer. 2010;46(5):920-925.

92. Bailey HH, Mahoney MR, Ettinger DS, et al. Phase II study of daily oral perifosine in patients with advanced soft tissue sarcoma. Cancer. 2006;107(10):2462-2467

93. Ghobrial IM, Roccaro A, Hong F, et al. Clinical and translational studies of a phase II trial of the novel oral Akt inhibitor perifosine in relapsed or relapsed/refractory Waldenstrom's macroglobulinemia. Clin Cancer Res. 2010;16(3):1033-1041.

94. Bendell JC, Nemunaitis J, Vukelja SJ, et al. Randomized placebo-controlled phase II trial of perifosine plus capecitabine as second- or third-line therapy in patients with metastatic colorectal cancer. J Clin Oncol. 2011;29(33):4394-4400.

95. Richardson PG, Wolf J, Jakubowiak A, et al. Perifosine plus bortezomib and dexamethasone in patients with relapsed/refractory multiple myeloma previously treated with bortezomib: results of a multicenter phase I/II trial. J Clin Oncol. 2011;29(32):4243-4249.

96. Li Z, Tan F, Liewehr DJ, Steinberg SM, Thiele CJ. In vitro and in vivo inhibition of neuroblastoma tumor cell growth by AKT inhibitor perifosine. J Natl Cancer Inst. 2010;102(11):758-770.

97. Li Z, Oh DY, Nakamura K, Thiele CJ. Perifosine-induced inhibition of akt attenuates brain-derived neurotrophic factor/TrkB-induced chemoresistance in neuroblastoma in vivo. Cancer. 2011;117(23):5412-5422.

98. Dasmahapatra GP, Didolkar P, Alley MC, Ghosh S, Sausville EA, Roy KK. In vitro combination treatment with perifosine and UCN-01 demonstrates synergism against prostate (PC-3) and lung (A549) epithelial adenocarcinoma cell lines. Clin Cancer Res. 2004;10(15):5242-5252.

99. Rahmani M, Reese E, Dai Y, et al. Coadministration of histone deacetylase inhibitors and perifosine synergistically induces apoptosis in human leukemia cells through Akt and ERK1/2 inactivation and the generation of ceramide and reactive oxygen species. Cancer Res. 2005;65(6):2422-2432. 
100. David E, Sinha R, Chen J, Sun SY, Kaufman JL, Lonial S. Perifosine synergistically enhances TRAIL-induced myeloma cell apoptosis via up-regulation of death receptors. Clin Cancer Res. 2008;14(16):5090-5098.

101. Huston A, Leleu X, Jia X, et al. Targeting Akt and heat shock protein 90 produces synergistic multiple myeloma cell cytotoxicity in the bone marrow microenvironment. Clin Cancer Res. 2008;14(3):865-874.

102. Pitter KL, Galban CJ, Galban S, et al. Perifosine and CCI 779 cooperate to induce cell death and decrease proliferation in PTEN-intact and PTEN-deficient PDGF-driven murine glioblastoma. PLoS One. 2011;6(1):e14545.

103. Engel JB, Honig A, Schonhals T, et al. Perifosine inhibits growth of human experimental endometrial cancers by blockade of AKT phosphorylation. Eur J Obstet Gynecol Reprod Biol. 2008;141(1): 64-69.

104. Papa V, Tazzari PL, Chiarini F, et al. Proapoptotic activity and chemosensitizing effect of the novel Akt inhibitor perifosine in acute myelogenous leukemia cells. Leukemia. 2008;22(1):147-160.

105. Becher OJ, Hambardzumyan D, Walker TR, et al. Preclinical evaluation of radiation and perifosine in a genetically and histologically accurate model of brainstem glioma. Cancer Res. 2010;70(6):2548-2557.
106. Iyer R, Evans AE, Qi X, et al. Lestaurtinib enhances the antitumor efficacy of chemotherapy in murine xenograft models of neuroblastoma. Clin Cancer Res. 2010;16(5):1478-1485.

107. Becher OJ, Trippett T, Kolesar J, et al. Phase I study of single-agent perifosine for recurrent pediatric solid tumors [abstract]. J Clin Oncol. 2010;28(15s):9540.

108. Becher OJ, Khakoo Y, Modak S, et al. Phase I study of single agent perifosine for recurrent pediatric solid tumors [abstract]. Advances in Neuroblastoma Research 2010: POC2.

109. Rodrik-Outmezguine VS, Chandarlapaty S, Pagano NC, et al. mTOR kinase inhibition causes feedback-dependent biphasic regulation of AKT signaling. Cancer Discov. 2011;1(3):248-259.

110. Spunt SL, Grupp SA, Vik TA, et al. Phase I study of temsirolimus in pediatric patients with recurrent/refractory solid tumors. J Clin Oncol. 2011;29(21):2933-2940.

111. Geoerger B, Kieran MW, Grupp S, et al. Phase II trial of temsirolimus in children with high-grade glioma, neuroblastoma and rhabdomyosarcoma. Eur J Cancer. 2012;48(2):253-262.
OncoTargets and Therapy

\section{Publish your work in this journal}

OncoTargets and Therapy is an international, peer-reviewed, open access journal focusing on the pathological basis of all cancers, potential targets for therapy and treatment protocols employed to improve the management of cancer patients. The journal also focuses on the impact of management programs and new therapeutic agents and protocols on

\section{Dovepress}

patient perspectives such as quality of life, adherence and satisfaction. The manuscript management system is completely online and includes a very quick and fair peer-review system, which is all easy to use. Visit http://www.dovepress.com/testimonials.php to read real quotes from published authors. 